\title{
SCIDoC
}

International Journal of Dentistry and Oral Science (IJDOS)

ISSN: 2377-8075

\section{Influence Of Suturing Materials On Wound Healing Following Periodontal Surgery}

Research Article

Kaviya L ${ }^{1}$, Arvina Rajasekar ${ }^{2 *}$

${ }^{1}$ Undergraduate Student, Saveetha Dental College and Hospitals, Saveetha Institute of Medical and Technical Sciences (SIMATS), Saveetha University, Chennai- 77, India.

${ }^{2}$ Senior Lecturer, Department of Periodontics, Saveetha Dental College and Hospitals, Saveetha Institute of Medical and Technical Sciences [SIMATS], Saveetha University, Chennai- 77, India.

\section{Abstract}

Background: Suture materials play an important role in the healing of wounds, enabling reconstruction and reassembly of tissue separated by a surgical procedure or a trauma. It helps in promoting healing and hemostasis.

Aim: The aim of this study was to assess the influence of absorbable and nonabsorbable suturing materials on wound healing following periodontal surgery.

Materials and Methods: The single centered cross-sectional study was conducted among 100 patients who had undergone periodontal flap surgery in the Department of Periodontics, Saveetha Dental College and Hospitals, Chennai, India. The patients were categorized based on the suturing materials used as follows: Group 1: Non absorbable materials (50 patients), Group 2: Absorbable materials (50 patients). After one week of periodontal flap surgery, wound healing index score was given for all the patients and compared. The data was analyzed using Statistical Package for Social Sciences (SPSS Software, Version 23.0). Frequency, percentage and Chi-square test were calculated.

Results: Majority of the patients with absorbable suturing materials $(30 \%)$ had better wound healing when compared with the patients with non absorbable suturing materials (14\%). The association between type of suturing materials and wound healing index was done by Chi square test and was found to be statistically significant with the $\mathrm{p}$ value of $0.032(\mathrm{p}<0.05)$.

Conclusion: The present study suggests that absorbable suturing materials showed better wound healing than non absorbable suturing materials following periodontal flap surgery.

Keywords: Healing; Wound; Innovative Technique; Suturing Materials; Periodontal Flap Surgery.

\section{Introduction}

Periodontitis is a chronic inflammatory disease which affects both the soft and hard tissues around the tooth. The primary etiology of the disease is bacterial plaque, however the disease is associated with various risk factors including age, gender, smoking, stress, socioeconomic status, genetic factors, systemic diseases and hormonal changes [1-9]. If the condition is left untreated, it leads to increase in pocket depth, gingival recession, clinical attachment loss, bone loss, furcation involvement, pathological migration and tooth mobility eventually leading to tooth loss [10-15].

The management of periodontitis involves scaling and root planning followed by flap surgery. In periodontal surgery, the most common method of wound closure is by sutures [16]. Suture ma- terials play an important role in the healing of wounds by reconstruction and of the tissue separated by any trauma or the surgical procedure by promoting healing and hemostasis. The primary function of the suture is to maintain wound closure and wound healing. Wound healing mainly depends on the formation and organization of the blood clot that is more resistant to mechanical forces acting on the flap and opposing surfaces in the wound closure $[17,18]$. The healing in periodontal and peri-implant defects are more complex processes than is wound healing in most other sites in the body [19]. There is evidence that suturing in periodontal surgery receives a higher degree of attention.

The wound healing process can be affected by the amount of suture material used, type of suturing material, suture type, suturing technique and the amount of tension on the suture. There is

*Corresponding Author:

Dr. Arvina Rajasekar,

Senior Lecturer, Department of Periodontics, Saveetha Dental College and Hospitals, Saveetha Institute of Medical and Technical Sciences [SIMATS], Saveetha University, Chennai- 77 , India.

Tel: +919486442309

E-mail: arvinar.sdc@saveetha.com

Received: September 13, 2021

Accepted: September 22, 2021

Published: September 23, 2021

Citation: Kaviya L, Arvina Rajasekar. Influence Of Suturing Materials On Wound Healing Following Periodontal Surgery. Int J Dentistry Oral Sci. 2021;8(9):4638-4641 doi: http://dx.doi.org/10.19070/2377-8075-21000945

Copyright: Dr. Arvina Rajasekar 2021 . This is an open-access article distributed under the terms of the Creative Commons Attribution License, which permits unrestricted use, distribution and reproduction in any medium, provided the original author and source are credited. 
a lack of information on the behavior of the suturing materials used in the oral cavity $[20,21]$. Oral environment is characterized by the presence of saliva, $\mathrm{pH}$, and the contents of immunoglobulins, bacteria that cause pathogenic effects by the accumulation of plaque on the surface of suturing material, especially on the knots [22]. Ideal suture materials have certain properties, such as resistance to traction, absence of memory, dimension stability, knot safety, and flexibility sufficient to avoid oral mucosa damage, limited bacterial adhesion, and contamination of the wound [23].

Suture materials are classified based on several criteria such as origin, structure, and biological properties. Based on origin, sutures can be natural and synthetic; by structure, they can be monofilament and multifilament and by biological properties, they can be absorbable and non-absorbable. The ideal choice of the suture material mainly depends on the size and depth of tissue to stitch. The use of non-absorbable materials (usually silk sutures) are used routinely, which are removed 5-7 days postoperatively [24, 25]. The important features of absorbable suture materials are their way of absorption will promote wound healing and loss of tensile strength over time. Superficial wound injury usually takes 5 to 10 days to heal, but the surgical procedures require sutures that persist 14 to 28 days. The absorbable suture materials are dissolved under the influence of proteolytic enzymes or hydrolysis [26-28].

Our team has extensive knowledge and research experience that has translated into high quality publications [29-48]. Through extensive literature search, it was revealed that there is a lack of adequate studies assessing the influence of suturing materials on wound healing following periodontal flap surgery. Hence, the rationale of this study was to assess the influence of absorbable and non-absorbable suturing materials on wound healing following periodontal surgery.

\section{Materials and Methods}

The single centered cross-sectional study was conducted among 100 patients who had undergone periodontal flap surgery in the Department of Periodontics, Saveetha Dental College and Hospitals, Chennai, India. The ethical clearance was obtained from the Institutional Ethical Committee and a written informed consent was obtained from all the study participants.
The patients were categorized based on the suturing materials used as follows: Group 1: Non absorbable materials (50 patients), Group 2: Absorbable materials (50 patients). After one week of periodontal flap surgery, all the patients were recalled for suture removal. After suture removal, wound healing index score based on Huang et al., 2005 was given for all the patients [49].

\section{Statistical Analysis:}

The data was analyzed using Statistical Package for Social Sciences (SPSS Software, Version 23.0). Descriptive and inferential statistics were done for data summarization and presentation. Frequency, percentage and Chi-square test were calculated.

\section{Results}

A total of 100 patients were enrolled. Of which 50 patients had undergone periodontal flap surgery with non-absorbable suturing materials and another 50 patients had undergone periodontal flap surgery with absorbable suturing materials. Wound healing index (WHI) scores were recorded and compared between both the groups.

Among 50 patients with non-absorbable suturing materials, 14 patients who underwent periodontal flap surgery showed WHI score of 1, 20 patients showed WHI score of 2 and 16 patients showed WHI score of 3 . Whereas, among 50 patients with absorbable suturing materials, 30 patients who underwent periodontal flap surgery showed WHI score of 1,14 patients showed WHI score of 2 and 6 patients showed WHI score of 3. Majority of the patients with absorbable suturing materials had better wound healing when compared with the patients with non-absorbable suturing materials. The association between type of suturing materials and wound healing index was done by Chi square test and was found to be statistically significant with the $\mathrm{p}$ value of 0.032 $(\mathrm{p}<0.05)$ (Figure 1).

\section{Discussion}

The present study was done to assess the influence of suturing materials on wound healing following periodontal flap surgery.

Closure of periodontal flap post surgically are essential for the establishment of primary union between flap margins. So the

Figure 1. The bar chart represents the association between Wound Healing Index (WHI) and the suturing materials in the patients who underwent periodontal flap surgery. $\mathrm{X}$ axis represents different suturing materials and $\mathrm{Y}$ axis represents the percentage of patients who had undergone periodontal flap surgery. Blue denotes WHI score of 1 and green colour denotes WHI score of 2 and brown colour denotes WHI score of 3. Majority of the patients with absorbable suturing materials $(30 \%)$ had better wound healing when compared with the patients with non-absorbable suturing materials (14\%). The association between type of suturing materials and wound healing index was done by Chi square test and was found to be statistically significant with the $\mathrm{p}$ value of $0.032(\mathrm{p}<0.05)$.

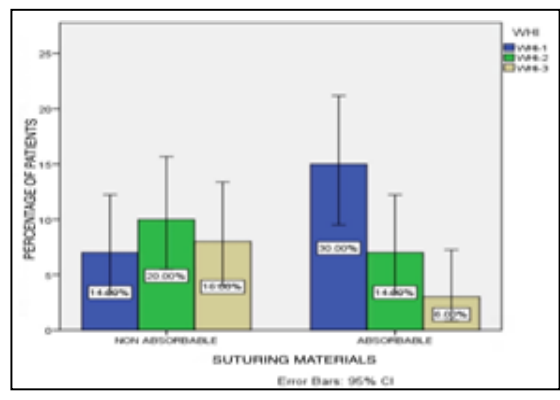


proper choice of surgical suture materials and techniques are most important for this process of healing. As a basic principle in periodontal surgery, atraumatic suture materials are used [50].

In this study absorbable suturing material has better wound healing as compared to non absorbable suturing material. Gazivoda $\mathrm{D}$ et al., studied the influence of suturing material on oral wound healing. In this study, three different absorbable synthetic suture materials (Catgut, Dexon and Vicryl rapide), commonly used in oral surgery were compared in terms of wound healing. The results showed that Vycril contributes to faster healing of human wounds, with fewer incidences of wound dehiscence and milder local reactions when compared to other materials [51]. Selvig KA et al., suggested that appropriate sutural material is crucial in reducing wound inflammation and absorbable suture materials improves wound healing [52].

Dragovic $\mathrm{M}$ et al., in his randomized controlled clinical trial compared different suture materials with respect to oral wound healing, microbial colonization, tissue reaction and clinical features. And found out that poor soft tissue healing was found around non absorbable suture materials and also this suture elicited more inflammatory reaction and microbial adherence [24]. Also, Duprez $\mathrm{K}$ et al., highlighted that absorbable suture material is the material of choice for oral surgeries in terms of tolerance, rapid resorption, the comfort of the patient and the cost [53].

Sergi S et al ., in his randomized clinical study evaluated the clinical and microbiological impact of absorbable and silk suture and found out that absorbable suturing material has lesser bacterial adherence as compared to non-absorbable suturing material [54]. The results obtained in the present study are in accordance with the previous studies as absorbable sutures showed better healing as compared to non-absorbable suture materials. However, future studies assessing the influence of different absorbable and non-absorbable suture materials, suturing technique, surgical procedure and the patient related factors on wound healing need to be conducted to confirm these findings.

\section{Conclusion}

The present study suggests that absorbable suturing materials showed better wound healing than non-absorbable suturing materials following periodontal flap surgery.

\section{Acknowledgement}

The author would like to acknowledge the help and support rendered by Saveetha Dental College and Hospitals, Saveetha Institute of Medical and Technical Sciences, Saveetha University, Chennai.

\section{Funding}

The present study is funded by

- Saveetha Institute of Medical and Technical Sciences

- Saveetha Dental College and Hospitals

- Saveetha University

- $\quad$ R.K.V Planers Private Ltd., Pattukkottai.

\section{References}

[1]. S T.A. et al. Assessment of tooth loss in chronic periodontitis patients with and without diabetes mellitus: A cross-sectional study. Int. J. Res. Pharm. Sci.2020; 11:1927-1931.

[2]. B G. et al.: Comparison of periodontal status among pregnant and nonpregnant women. Int. J. Res. Pharm. Sci.2020; 11:1923-1926.

[3]. Rajasekar A. et al.: Assessment Of Periodontal Status among Post Menopausal Women: A Retrospective Study. Int. J. Dent. Oral Sci.2020: 1063-1066.

[4]. Kandhan TS, Rajasekar A. Prevalence of Periodontal Diseases Among Patients with And Without Systemic Diseases-A Retrospective Study. J. Complement. Med. Res.. 2020;11(4):155-62.

[5]. SHUKRI N, MOHAMED M, SEKAR AR, SUBRAMANIAM AB. Assessment of periodontal health among patients with diabetes mellitus: a retrospective study. J. contemp. issues bus. gov. 2020 Dec 11;26(2):28-34.

[6]. SHAH P, RAJASEKAR A, CHAUDHARY M. Assessment of Gender Based Difference in Occurrence of Periodontal Diseases: A Retrospective Study. J. contemp. issues bus. gov. 2021 Feb 16;27(2):521-6.

[7]. MOHD AZLAN SUNIL NS, RAJASEKAR A, DURAISAMY R. Evaluation of Periodontal Health Adjacent to Class V Restoration. J. contemp. issues bus. govt. 2021 Feb 15;27(2):324-9.

[8]. RAJASEKAR A, CHAUDARY M. Prevalence of Periodontal Diseases Among Individuals Above 45 Years: A Retrospective Study. J. contemp. issues bus. govt. $2021 \mathrm{Feb}$ 19;27(2):527-33.

[9]. Rajasekar A, Mathew MG. Prevalence of Periodontal Disease among Individuals between 18-30 Years of Age: A Retrospective Study. Ann. Med. Health Sci. Res. 2021 Jun 30.

[10]. Rajeshwaran N, Rajasekar A, Kaarthikeyan G. Prevalence of Pathologic Migration in Patients with Periodontitis: A Retrospective Analysis. J. Complement. Med. Res. 2020;11(4):172-8.

[11]. KARTHIKEYAN MURTHYKUMAR DR, KAARTHIKEYAN DG. Prevalence of Tooth Loss Among Chronic Periodontitis Patients-A Retrospective Study. Int. J. Pharm. Res. 2020 Jul;12(2).

[12]. Murthykumar K. et al.: Assessment of various treatment modalities for isolated gingival recession defect- A retrospective study.: Int. j. res. pharm. sci.2020; 11:3-7.

[13]. Sabarathinam J. et al.: Prevalence of Furcation Involvement Among Patients with Periodontitis: A Cross Sectional Study.: Int. j. res. pharm. sci.2020; 11:1483-1487.

[14]. Rajeshwaran N, Rajasekar A. Prevalence of Angular Bone Defects in Chronic Periodontitis Patients with and without Systemic Diseases. Indian J. Forensic Med. Toxicol. 2020 Oct 1;14(4).

[15]. Evaluation of Antiplaque and Antigingivitis Effects of A Herbal Mouthwash: Int. J. Pharm. Res.2021; 13.

[16]. Karde PA, Sethi KS, Mahale SA, Mamajiwala AS, Kale AM, Joshi CP. Comparative evaluation of two antibacterial-coated resorbable sutures versus noncoated resorbable sutures in periodontal flap surgery: A clinico-microbiological study. J Indian Soc Periodontol. 2019 May-Jun;23(3):220-225. Pubmed PMID: 31143002.

[17]. Burkhardt R, Lang NP. Influence of suturing on wound healing. Periodontol 2000. 2015 Jun;68(1):270-81.

[18]. Garg A.K.Wound Healing and Suturing Techniques in Dental Implant Surgery. Implant Dent.2010: 103-111.

[19]. Trombelli L., R. Farina. Flap Designs for Periodontal Healing. Oral Wound Healing.2013:229-242.

[20]. Alexandrescu V, editor. Wound Healing: New Insights into Ancient Challenges. BOD. 2016 Oct 12.

[21]. Sculean A, Aroca-Sotelo S, Robert R.. Azzi, Bolz W. Periodontal regenerative therapy. Quintessence; 2010.

[22]. Gazivoda D, Pelemiš D, Vujašković G. A clinical study on the influence of suturing material on oral wound healing. Vojnosanit Pregl. 2015;72(9):7659.

[23]. Javed F, Al-Askar M, Almas K, Romanos GE, Al-Hezaimi K. Tissue reactions to various suture materials used in oral surgical interventions. ISRN Dent. 2012;2012: 762095 .

[24]. Dragovic M, Pejovic M, Stepic J, Colic S, Dozic B, Dragovic S, et al. Comparison of four different suture materials in respect to oral wound healing, microbial colonization, tissue reaction and clinical features-randomized clinical study. Clin Oral Investig. 2020 Apr;24(4):1527-1541.Pubmed PMID: 31342245.

[25]. Yool D.A. Suture materials, staples, and tissue adhesive. Small animal soft tissue surgery. 2012:29-38.

[26]. Taysi AE, Ercal P, Sismanoglu S. Comparison between tensile characteristics of various suture materials with two suture techniques: an in vitro study. Clin. Oral Investig. 2021 Apr 14:1-9. 
[27]. Mirković S, Đurđević-Mirković T, Bajkin B, Šarčev I. Choice of surgical suture material used in oral cavity: Clinical study. Med. Pregl. 2010;63(78):497-501.

[28]. Arcuri C, Cecchetti F, Dri M, Muzzi F, Bartuli FN. Suture in oral surgery. A comparative study. Minerva Stomatol. 2006 Jan 1;55(1-2):17-31.

[29]. Ramesh A, Varghese S, Jayakumar ND, Malaiappan S. Comparative estimation of sulfiredoxin levels between chronic periodontitis and healthy patients - A case-control study. J Periodontol. 2018 Oct;89(10):1241-1248.Pubmed PMID: 30044495 .

[30]. Paramasivam A, Priyadharsini JV, Raghunandhakumar S, Elumalai P. A novel COVID-19 and its effects on cardiovascular disease. Hypertens. Res. $2020 \mathrm{Jul} ; 43(7): 729-30$.

[31]. S G, T G, K V, Faleh A A, Sukumaran A, P N S. Development of 3D scaffolds using nanochitosan/silk-fibroin/hyaluronic acid biomaterials for tissue engineering applications. Int J Biol Macromol. 2018 Dec;120(Pt A):876885.Pubmed PMID: 30171951.

[32]. Del Fabbro M, Karanxha L, Panda S, Bucchi C, Doraiswamy JN, Sankari $\mathrm{M}$, et al. Autologous platelet concentrates for treating periodontal infrabony defects Cochrane Database Syst. Rev. 2018;11: CD011423.

[33]. Paramasivam A, Vijayashree Priyadharsini J. MitomiRs: new emerging microRNAs in mitochondrial dysfunction and cardiovascular disease. Hypertens Res. 2020 Aug;43(8):851-853.Pubmed PMID: 32152483.

[34]. Jayaseelan VP, Arumugam P. Dissecting the theranostic potential of exosomes in autoimmune disorders. Cell Mol Immunol. 2019 Dec;16(12):935-936. Pubmed PMID: 31619771.

[35]. Vellappally S, Al Kheraif AA, Divakar DD, Basavarajappa S, Anil S, Fouad $\mathrm{H}$. Tooth implant prosthesis using ultra low power and low cost crystalline carbon bio-tooth sensor with hybridized data acquisition algorithm. Comput. Commun. 2019 Dec 15;148:176-84.

[36]. Vellappally S, Al Kheraif AA, Anil S, Assery MK, Kumar KA, Divakar DD. Analyzing Relationship between Patient and Doctor in Public Dental Health using Particle Memetic Multivariable Logistic Regression Analysis Approach (MLRA2). J Med Syst. 2018 Aug 29;42(10):183.Pubmed PMID: 30155746.

[37]. Varghese SS, Ramesh A, Veeraiyan DN. Blended Module-Based Teaching in Biostatistics and Research Methodology: A Retrospective Study with Postgraduate Dental Students. J Dent Educ. 2019 Apr;83(4):445-450.Pubmed PMID: 30745352

[38]. Venkatesan J, Singh SK, Anil S, Kim SK, Shim MS. Preparation, Characterization and Biological Applications of Biosynthesized Silver Nanoparticles with Chitosan-Fucoidan Coating. Molecules. 2018 Jun 12;23(6):1429.Pubmed PMID: 29895803.

[39]. Alsubait SA, Al Ajlan R, Mitwalli H, Aburaisi N, Mahmood A, Muthurangan $\mathrm{M}$, et al. Cytotoxicity of different concentrations of three root canal sealers on human mesenchymal stem cells. Biomolecules. 2018 Sep;8(3):68.

[40]. Venkatesan J, Rekha PD, Anil S, Bhatnagar I, Sudha PN, Dechsakulwatana C, et al. Hydroxyapatite from cuttlefish bone: isolation, characterizations, and applications. Biotechnol. Bioprocess Eng. 2018 Aug;23(4):383-93.
[41]. Vellappally S, Al Kheraif AA, Anil S, Wahba AA. IoT medical tooth mounted sensor for monitoring teeth and food level using bacterial optimization along with adaptive deep learning neural network. Measurement. $2019 \mathrm{Mar}$ $1 ; 135: 672-7$.

[42]. PradeepKumar AR, Shemesh H, Nivedhitha MS, Hashir MMJ, Arockiam S, Uma Maheswari TN, et al. Diagnosis of Vertical Root Fractures by Conebeam Computed Tomography in Root-filled Teeth with Confirmation by Direct Visualization: A Systematic Review and Meta-Analysis. J Endod. 2021 Aug;47(8):1198-1214.Pubmed PMID: 33984375.

[43]. R H, Ramani P, Tilakaratne WM, Sukumaran G, Ramasubramanian A Krishnan RP. Critical appraisal of different triggering pathways for the pathobiology of pemphigus vulgaris-A review. Oral Dis. 2021 Jun 21.Pubmed PMID: 34152662.

[44]. Ezhilarasan D, Lakshmi T, Subha M, Deepak Nallasamy V, Raghunandhakumar $S$. The ambiguous role of sirtuins in head and neck squamous cell carcinoma. Oral Dis. 2021 Feb 11.Pubmed PMID: 33570800.

[45]. Sarode SC, Gondivkar S, Sarode GS, Gadbail A, Yuwanati M. Hybrid oral potentially malignant disorder: A neglected fact in oral submucous fibrosis. Oral Oncol. 2021 Oct;121:105390.Pubmed PMID: 34147361.

[46]. Kavarthapu A, Gurumoorthy K. Linking chronic periodontitis and oral cancer: A review. Oral Oncol. 2021 Oct;121:105375.Pubmed PMID: 34140233.

[47]. Vellappally S, Al-Kheraif AA, Anil S, Basavarajappa S, Hassanein AS. Maintaining patient oral health by using a xeno-genetic spiking neural network .J. Ambient Intell. Humaniz. Comput. 2018 Dec 14:1-9.

[48]. Aldhuwayhi S, Mallineni SK, Sakhamuri S, Thakare AA, Mallineni S, Sajja R, et al. Covid-19 Knowledge and Perceptions Among Dental Specialists: A Cross-Sectional Online Questionnaire Survey. Risk Manag Healthc Policy. 2021 Jul 7;14:2851-2861.Pubmed PMID: 34262372.

[49]. Huang LH, Neiva RE, Wang HL. Factors affecting the outcomes of coronally advanced flap root coverage procedure. J. Periodontol. 2005 Oct;76(10):1729-34.

[50]. Pippi R. Post-Surgical Clinical Monitoring of Soft Tissue Wound Healing in Periodontal and Implant Surgery. Int J Med Sci. 2017 Jul 18;14(8):721-728. Pubmed PMID: 28824306.

[51]. Gazivoda D, Pelemiš D, Vujašković G, Đurđević S. Influence of suturing material on wound healing: An experimental study on dogs. Vojnosanitetski pregled. 2015;72(5):397-404.

[52]. Selvi R. Breast diseases: imaging and clinical management. Springer; 2014 Dec 5.

[53]. Duprez K, Bilweis J, Duprez A, Merle M. Experimental and clinical study of fast absorption cutaneous suture material. Ann Chir Main. 1988;7(1):91-6. Pubmed PMID: 3044289.

[54]. Sala-Pérez S, López-Ramírez M, Quinteros-Borgarello M, Valmaseda-Castellón E, Gay-Escoda C. Antibacterial suture vs silk for the surgical removal of impacted lower third molars. A randomized clinical study. Med Oral Patol Oral Cir Bucal. 2016 Jan 1;21(1):e95-102.Pubmed PMID: 26615503. 